\title{
Canadian Association of Gastroenterology and the Canadian Digestive Health Foundation: Guidelines on colon cancer screening
}

\author{
Desmond Leddin MB FRCPC ${ }^{1}$, Richard Hunt MB FRCPC FACG FRCPEd ${ }^{2}$, Malcolm Champion M B ChB M RCS LRCP \\ FRCPUK FRCPC ${ }^{3}$, Alan Cockeram MD FRCPC DABIM ${ }^{4}$, Nigel Flook MD CCFP FCFP5, Michael Gould MD FRCPC 6 , \\ Young-In Kim MD FRCPC ${ }^{6}$, Jonathan Love MD FRCPC ${ }^{4}$, David Morgan MD FRCPC MSc ${ }^{2}$, Susan Natsheh MD FRCPC BM Sc ${ }^{7}$, \\ Dan Sadowski MD FRCPC ABIM 5 , for the Canadian Association of Gastroenterology and the Canadian Digestive \\ Health Foundation committee on colon cancer screening
}

\section{POSITION}

The Canadian A ssociation of $\mathrm{G}$ astroenterology ( $\mathrm{CA} \mathrm{G}$ ) and the $\mathrm{C}$ anadian Digestive $\mathrm{H}$ ealth Foundation (CDHF) strongly support the establishment of screening programs for colorectal cancer. The test that is used for screening should be determined by patient preference, current evidence and local resources.

\section{BACKGROU N D}

The technical report by the $\mathrm{National}$ Committee on $\mathrm{C}$ olorectal $\mathrm{C}$ ancer Screening prepared for $\mathrm{H}$ eal th $\mathrm{C}$ anada contains a comprehensive review of the subject, which can be found at <www.hc-sc.gc.ca/pphb-dgspsp/publicat/ncccs-cndec/ intro_e.html>.

Colorectal cancer is the third most prevalent cancer affecting both men and women in C anada (1), with 20,000 cases annually. O ne-third of people afflicted with this cancer will die of the disease (2).

$M$ any of these cancers are preventable. There is good evidence that most colorectal cancers arise from precursor adenomatous polyps (3). Removal of these polyps can prevent subsequent development of cancer. Screening may allow detection of tumours at an early stage, which would improve the prognosis (4). Ideally, therefore, a screening program for colon cancer would permit detection of precancerous polyps and allow earlier detection of established cancers.

A bout $5 \%$ of colon cancers are associated with gen etically defined colon cancer family syndromes, and $20 \%$ to $30 \%$ of all colon cancers have a potentially definable inherited cause (5). In the absence of defined genetic syndromes, three variables affect the risk of colon cancer: age, past medical history and family history. The risk of colorectal cancer increases with age. It is estimated that the incidence of colon cancer in the next 10 years is 1 in 500 for persons 40 to 49 years of age, but increases to about 1 in 125 in the 50- to 59-year-old age group (6). Long-standing inflammatory bowel disease predisposes to colon cancer as does a previous history of polyps or colon cancer. A history of colon cancer in a first-degree relative also increases the risk, especially if more than one relative is affected or if the relative is diagnosed before age 45 years (7).

These variables form the basis for risk stratification. $H$ igher risk is associated with age over 50 years or having at least one first-degree relative with cancer (especially with onset under age 50 years). Conversely, persons under 50 years of age without a family history of colon cancer are at lower risk.

There are several diagnostic tools that can be used for screening. Three factors determine the choice of modality: the operational characteristics of the tool, the risk of cancer in the screened population and the feasibility of applying the technique to the population to be screened. Tests that can readily be applied to the population at large may not necessarily have the best operational characteristics. For example, fecal occult blood testing (FOBT), which may be appropriate for general population screening, is not considered sufficiently sensitive for screening of high risk patients.

The provider's perspective also influences the choice of screening technique. A physician may recommend a course of action for an individual patient that could not be justified from a population health perspective.

Colon cancer screening entails more than performing a test. A screening program involves family physicians, nurses, genetic counsellors, radiologists and surgeons, as well as gastroenterologists. Education programs aimed at medical professionals and the public enhance the acceptance of screening programs and help ensure their appropriateness, efficacy and efficiency.

\section{CURRENT ACCESS T O GAST ROENTEROLOGY SPECIALIST CARE}

A Ithough it has not been studied formally, in put to the C A G regional committees indicates that access to gastrointestinal

D epartments of $\mathrm{M}$ edicine, ${ }^{1} \mathrm{Q}$ ueen Elizabeth II H ealth Sciences $\mathrm{C}$ entre, $\mathrm{H}$ alifax, $\mathrm{N}$ ova Scotia; ${ }^{2} \mathrm{M}$ cM aster U niversity, $\mathrm{H}$ amilton, $\mathrm{O}$ ntario;

${ }^{3} \mathrm{U}$ nversity of $\mathrm{O}$ ttawa, $\mathrm{O}$ ttawa, $\mathrm{O}$ ntario; ${ }^{4} \mathrm{D}$ alhousie $U$ niversity, $\mathrm{H}$ alifax, $\mathrm{N}$ ova Scotia; ${ }^{5} \mathrm{D}$ epartment of $\mathrm{F}$ amily $\mathrm{M}$ edicine, $\mathrm{U}$ niversity of A lberta, Edmonton, A lberta; ${ }^{6} \mathrm{D}$ epartment of M edicine, U niversity of Toronto, Toronto, $\mathrm{O}$ ntario; ${ }^{7} \mathrm{D}$ epartment of M edical Education, Saint John Regional H ospital, Saint John, N ew Brunswick

C orrespondence: Dr Desmond Leddin, Division of G astroenterology, Room 912, Victoria Building, Victoria G eneral H ospital Site, Q EII,

1278 Tower Road, H alifax, N ova Scotia B3H 2Y9. Telephone 902-473-7833, fax 902-473-4406, e-mail desmond. leddin@dal. ca

Reprints: C A G N ational O ffice, 2902 South Sheridan Way, O akville, O ntario L6] 7L 6. Telephone: 905-829-2504, toll free 1-888-780-0007,

fax 905-829-0242, e-mail cagoffice@cag-acg.org 
(GI) specialty care varies across the country. Timely emergency care is generally available but wait times for elective GI consultation are three to 10 months. It is clear that, in many parts of $C$ anada, access to special ist $\mathrm{GI}$ care is limited. This problem needs to be addressed, and additional human and physical resources acquired, before new cancer screening programs are initiated. In other regions, it appears that the resources are in place but are underutilized due to financial and other constraints.

\section{CANADIAN, BRITISH AND AMERICAN GU IDELINES}

We are indebted to our A merican and British colleagues for their work in preparing practice guidelines $(8,9)$. The CA G CDHF group has reached the same conclusions based on our review of the evidence. The guidelines outlined here are very similar to those of the A merican $G$ astroenterology A ssociation ( $A G A$ ) and the British Society of Gastroenterology (BSG) on screening of high risk groups. We differ only in that we recommend fecal occult blood testing every two years instead of every year, and we suggest that clinical judgement determine the type of follow-up for advanced adenomas (instead of colonoscopy after three years, as in the A G A guidelines).

\section{ST RATIFICATION OF RISK OF COLON CANCER}

The majority of the population does not have an affected relative and is at average risk of developing colorectal cancer. Taking the population as a whole, it has been estimated that a 50 -year-old person has a $6 \%$ lifetime risk of developing this tumour.

Certain groups are at higher than average risk. The largest such group comprises patients who have a first-degree relative with colon cancer. The risk is especially high if colon cancer or other related cancers occur in young persons in more than one generation. The family history in these cases may be indicative of an underlying gen etic defect. Patients with a history of familial adenomatous polyposis (FA P) or hereditary nonpolyposis colon cancer are also at significantly increased risk (10), as are those with long-standing inflammatory bowel disease (11).

A t present there is no $\mathrm{C}$ anadian approach to screening of high risk patients. FO BT does not have adequate sen sitivity. A screening program for colon cancer must consider the resources needed for endoscopic screening of high risk patients.

Patients testing positive for occult blood should undergo colonoscopy because colon cancer will be found in about $12 \%$ (12).

\section{SCREEN IN G OPTIONS}

Detailed information on the operating characteristics of screening tests is available at <http://www.hc-sc.gc.ca/pphbdgspsp/publicat/ncccs-cndcc/intro_e.html>. That review is extensively referenced. The intent of the present article is to summarize the advantages and disadvantages of each testing modality.

\section{FOBT}

The major advantage of FOBT is the relative ease of initial testing. The test can be administered by the patient or at the primary care level, and does not require technical expertise or specialist referral.
Disadvantages include poor sensitivity and specificity. Logistical difficulties arise for primary care practitioners who are responsible for scheduling the test. In addition, the test is designed to detect cancers at an early stage and not specifically to interrupt the polyp-cancer sequence. Therefore, it is more an early detection strategy rather than a truly preventive technique.

Feasibility: No Canadian clinical trial data are available, but the feasibility of FOBT has been studied in detail by $\mathrm{H}$ ealth Canada using computer modelling <http://www.hcsc.gc.ca/pphb-dgspsp/publicat/ncccs-cndcc/index.html >. Based on $\mathrm{H}$ ealth $\mathrm{C}$ anada projections we can estimate that 1 to 1.5 full-time gastroenterologists (or equivalent) would be required to screen 100,000 persons.

\section{Colonoscopy}

The advantages of this test are its high sensitivity and specificity for the detection of both polyps and carcinomas, provided that there is a complete examination of a well-prepared colon. C ontrolled studies of efficacy are lacking but most gastroenterologists would agree that colonoscopy is the gold standard test.

The major disadvantage of this test is that it requires considerable physical resources and skilled personnel. Expertise is required to successfully and safely pass the colonoscope to the cecum and to undertake polypectomy. Complications can result from sedation and the risk of perforation or bleeding is approximately 1:1000 to $1: 2000$ cases (with rare fatalities). Patient adherence may be limited by the fact that the test can be uncomfortable, even with sedation. Some lesions are missed. M oreover, in approximately $5 \%$ of cases, it is not possible to visual ize the entire colon, either because of poor preparation or a technically difficult bowel.

Feasibility: There have been no studies estimating the number of colonoscopies that would be required to screen the averagerisk population in Canada if this were the primary screening tool. $\mathrm{N}$ or is it known what percentage of the at-risk population already undergo colonoscopy each year. Waiting lists for nonscreening diagnostic colonoscopy vary considerably throughout $\mathrm{C}$ anada, and it is unlikely that a colonoscopic screening program could be put in place, in any part of the country, without significant further investment in human and physical resources.

It is generally accepted that colonoscopy is the appropriate screening tool for high risk individuals, but there is currently no organized program to provide screening for these individuals. The magnitude of the problem and required resources are not known.

\section{Flexible sigmoidoscopy}

The advantage of flexible sigmoidoscopy is that it is sensitive and specific for distal colonic lesions. The test can be performed by nurses or by nonspecialist physicians.

The disadvantage is that some patients have proximal tumours only, which would escape detection. The risk of perforation is minimal.

Feasibility: As with colonoscopy, the human and physical resources are not in place to institute a national flexible sigmoidoscopy-based program. The amount of resources required is not known.

Debate continues as to whether it is necessary to perform colonoscopy on every patient in whom a distal colonic 


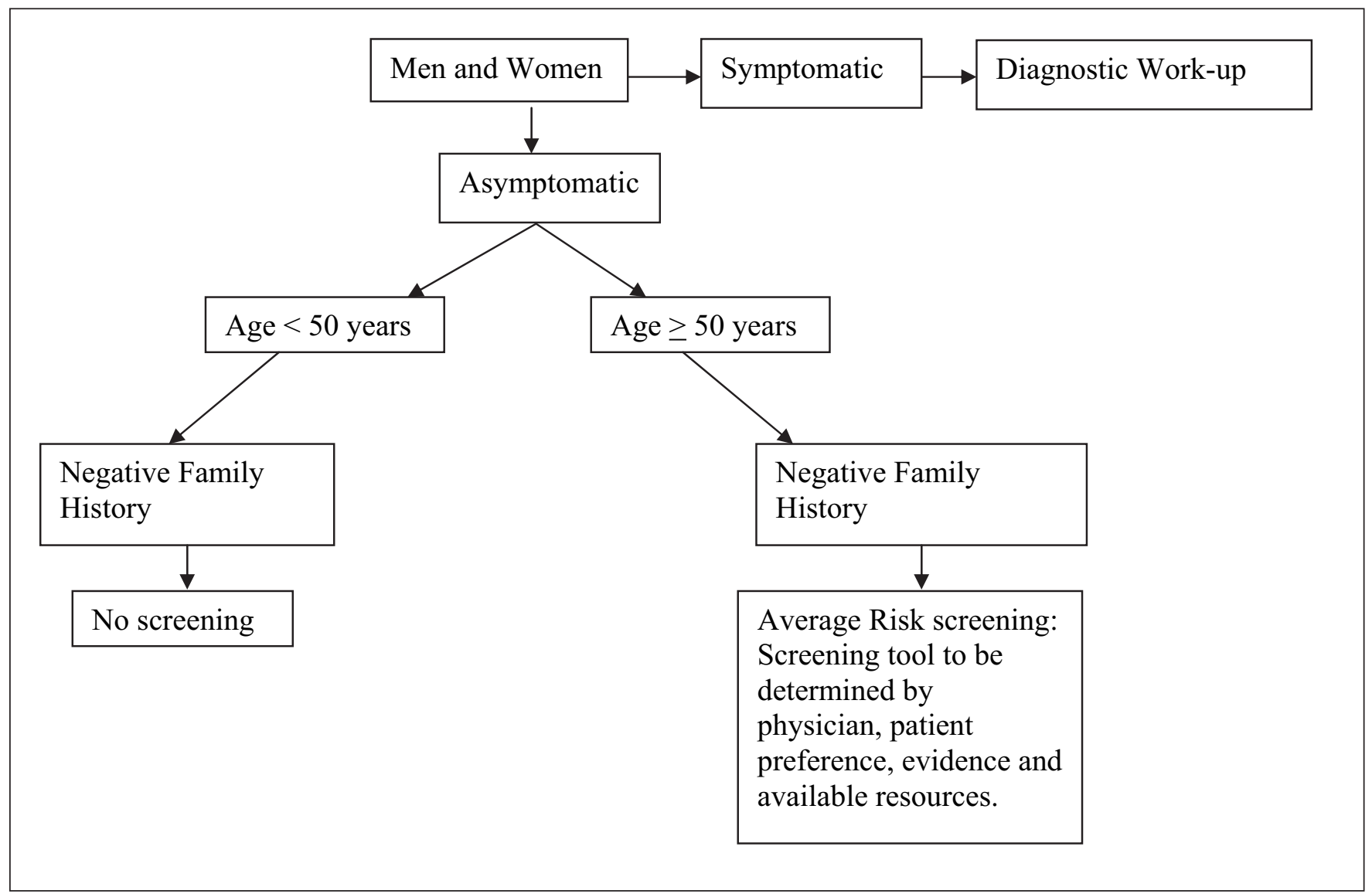

Figure 1) A pproach to average risk screening

adenoma has been detected. The CA G-CDH F position is that colonoscopy should be offered to all such patients, but further studies are awaited.

\section{Flexible sigmoidoscopy combined with FO BT}

There are limited data on the use of combination screening. It is likely to enhance the detection rate compared with FOBT alone, but at the cost of increased workload demands. No $\mathrm{C}$ anadian feasibility data are available.

\section{D ouble contrast barium enema}

The major advantage of this test is that it can be performed by radiology technicians. Furthermore, barium $\mathrm{x}$-rays permit evaluation of the entire colon.

Disadvantages include the fact that it is less sensitive and specific than colonoscopy, because of the presence of retained stool. A bnormalities need to be followed up with colonoscopy. The test involves radiation exposure, but there is no evidence that this is a significant problem.

Feasibility: This test is feasible in that an extensive radiological infrastructure already exists in most health care institutions. Therefore, a radiology-based population screening program could take place without significant additional human and infrastructure investment. On the other hand, many radiology facilities are already working at maximum capacity. The amount of resources required is not known.

\section{RECOMMEN DATIONS}

\section{Screening of individuals at average risk}

Colon cancer is uncommon before the age of 50 years. The probability of developing colon cancer in the next 10 years is $1: 1000$ in the 30 to 39 age group, 1:125 in the 50 to 59 age group and 1:50 at age 60 to 69 years(7). M ost authorities recommend that screening be offered to persons aged 50 to 65 years. This age group constitutes approximately $20 \%$ of the Canadian population.

The CAG and CDHF endorse the algorithm shown in Figure 1, which is similar, but not identical, to that in the A GA guidelines (8).

Symptomatic individuals cannot be considered as screening candidates. They need appropriate diagnostic work up. A symptomatic individuals below the age of 50 years are unlikely to have colon cancer and screening this group is not considered helpful. The strategies outlined below each have advantages and disadvantages. We do not contend that they are equally effective nor should this idea be suggested to patients.

Individuals over the age of 50 years with a negative family history should undergo screening with one of the following strategies:

1. FOBT every two years. The A GA guidelines recommend screening yearly using a guaiac-based test with dietary restrictions or an immunochemical test for heme without restrictions; 
N ote: The $\mathrm{C}$ anadian Expert Panel commissioned by $\mathrm{H}$ ealth $\mathrm{C}$ anada recommended occult blood testing every two years. A lthough yearly occult blood testing does increase the detection of cancer as compared with every two years, it was not felt that this justified the resulting considerable increase in workload. In addition, testing every two years would be more achievable from a primary care perspective. The CA G-CDH F supports the position taken by the $\mathrm{H}$ ealth $\mathrm{C}$ anada committee and recommends that, if FO BT is used, it be performed every two years.

2. Flexible sigmoidoscopy every five years. The interval of five years between examinations is shorter than that recommended if colonoscopy is used, because flexible sigmoidoscopy may be less sensitive than colonoscopy even in the area examined, or;

\section{Flexible sigmoidoscopy combined with FOBT every} five years. The rationale for the interval is mentioned above, or;

4. D ouble contrast barium enema every five years. The lesser sensitivity and specificity of this test compared with colonoscopy is the rationale for the shorter screening interval compared with colonoscopy, or;

5. C olonoscopy every $\mathbf{1 0}$ years. The high sensitivity and specificity of this test means that the interval between tests can be twice as long as that of the other tests mentioned above.

\section{Screening of individuals at higher risk}

Some groups are at increased risk of colon cancer. These include patients who have first-degree relatives with the disease, a family history that suggests a definable genetic abnormality, FAP or long-standing colonic inflammatory bowel disease. $G$ enetic counselling is an important part of the management of patients with these conditions. There should be provincial strategies to ensure timely access to all appropriate services including genetic counselling and testing.

The CA G and CDHF guidelines are similar to those of the A GA (8). These are reproduced in modified form (Figure 2).

\section{HIGH RISK GROUPS: DEFIN ITIONS, CRITERIA FOR DIAGNOSIS, AND RATIONALE FOR SCREEN ING RECOMMENDATIONS}

The timing of initial colonoscopy and repeat examinations is based on our current understanding of the natural history of colonic polyps and cancer in the populations at risk. For example, screening for patients with HNPCC begins at an earlier age than that for persons who have no first-degree relatives with colon cancer.

\section{Colonic polyps}

Both histology and the degree of dysplasia are affected by adenoma size. Larger polyps are more likely to have a villous component and are more likely to be dysplastic. Villous change is associated with a greater risk of high-grade dysplasia and cancer.
The term low grade dysplasia is now generally used to describe polyps with mild or moderate dysplasia. High-grade dysplasia denotes severe dysplastic change or carcinoma in situ. Invasive cancer means that neoplastic cells have spread through the muscularis mucosa.

Diminutive polyps, which are less than $5 \mathrm{~mm}$, are common. The malignant potential of these lesions is being studied. Current recommendations are for follow-up colonoscopy at five years, but this interval might be increased in the near future.

The term advanced adenoma does not have a uniform definition in the literature $(13,14)$. Some authors refer to invasive cancer while others do not. The A GA guidelines did not define advanced adenoma (8). We use the term for polyps larger than $1 \mathrm{~cm}$ in diameter or those with either a villous component or high-grade dysplasia, as defined above. Given the significant intraobserver variability when evaluating these lesions and the paucity of outcomes data (13), we recommend that follow-up intervals be based on clinical judgement. Similarly, follow-up for patients with numerous adenomas, large sessile polyps and malignancy should be determined by assessment of the overall clinical situation. Follow-up examination should be performed after a shorter interval than that for polyps with less ominous histology.

\section{H ereditary nonpolyposis colorectal cancer}

The criteria for the diagnosis of hereditary non polyposis colorectal cancer (HN PCC) are:

A t least three relatives with an H N PCC -associated cancer (involving the colon or rectum, endometrium, small bowel, ureter or renal pelvis) (15), plus:

1. O ne or more relatives with colorectal cancer diagnosed under the age of 50 years;

2. Colorectal cancer involving persons in two or more successive generations;

3. O ne affected patient is a first-degree relative of the other two;

\section{FA P is excluded; and}

5. Tumours are verified by histological examination.

FA P

FA $P$ is an autosomal dominant condition associated with the presence of hundreds, or even thousands, of colonic polyps. The polyps usually develop during the teenage years but they can occur in the first decade of life. Because the polyps are almost always found in the rectum as well as in the rest of the colon, sigmoidoscopy is an appropriate screening tool.

\section{A ttenuated FA P or attenuated adenomatous polyposis coli}

A tten uated adenomatous polyposis coli is similar to classical FA P but has a somewhat different genetic basis and results in fewer polyps. Because the polyps often first appear in the right colon, sigmoidoscopy is not adequate for screening. Onset of polyposis is 10 years later than onset of classical FA P; therefore, screening is begun somewhat later. 


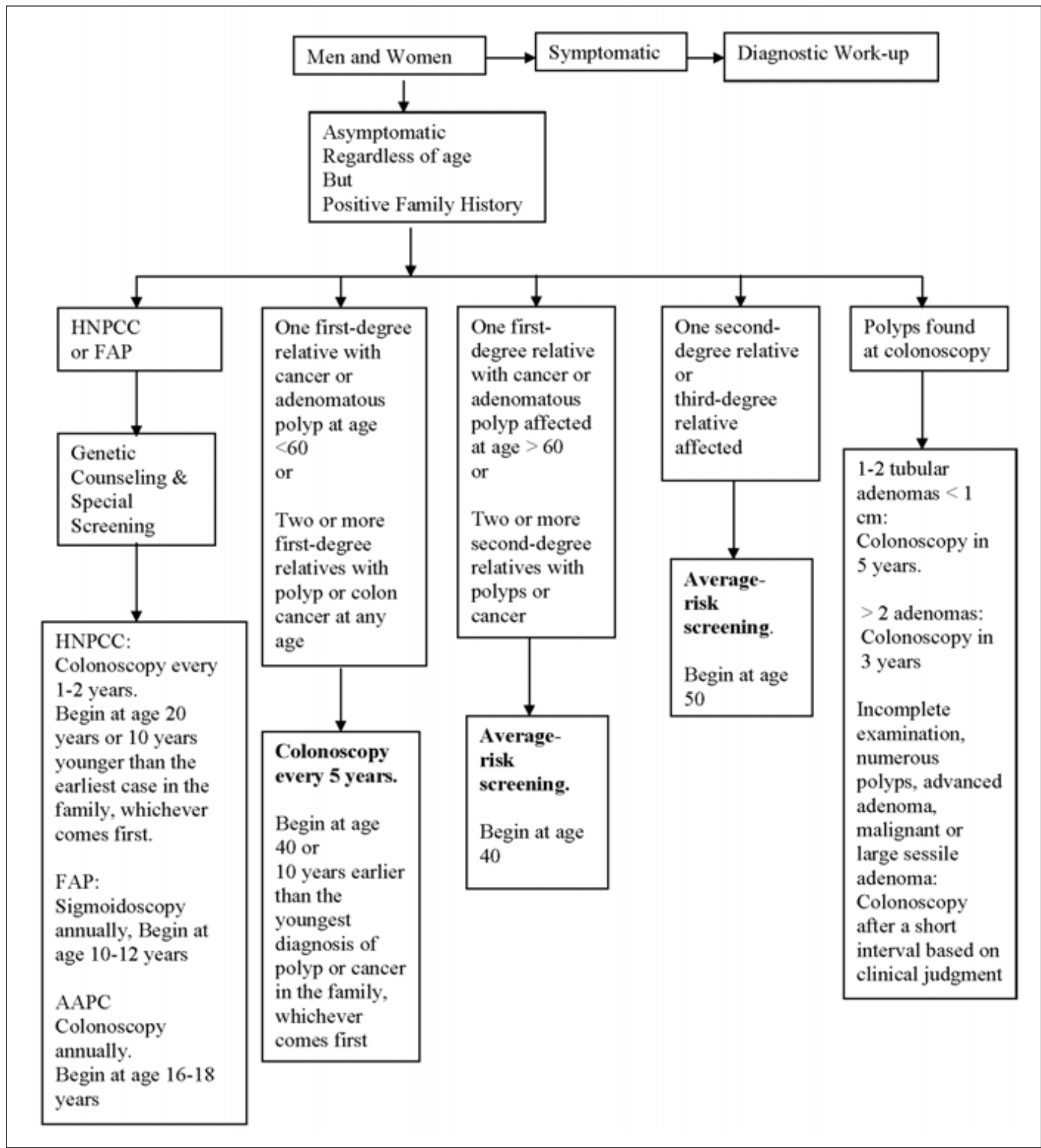

Figure 2) A pproach to higher risk screening. A A PC A ttenuated adenomatous polyposis; FA P F amilial adenomatous polyposis; First-degree relative Parents, siblings, children; H N PCC H ereditary nonpolyposis colorectal cancer; Second-degree G randparent, aunt or uncle; Third-degree G reat grandparent or cousin

OTHER HIGHER RISK GROUPS

Previous history of colorectal cancer

A colonoscopy should be done preoperatively, or soon after, to exclude synchronous lesions. If this examination is normal, then the next colonoscopy can be performed three years later, and, if that is normal, five years thereafter. This recommen dation is similar to that of the BSG (9).

Previous history of inflammatory bowel disease

The cancer risk is similar for C rohn's disease and ulcerative 


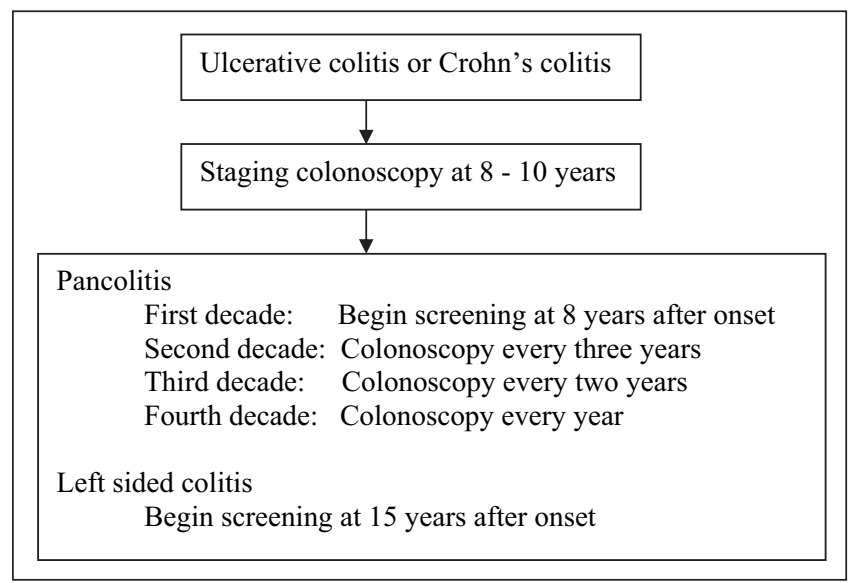

Figure 3) British Society of $G$ astroenterology approach to screening and surveillance in inflammatory bowel disease

colitis; thus, recommendations are the same for both. A II patients should have a colonoscopy eight to 10 years after disease onset to help determine the extent of disease. Regular surveillance should begin after eight to 10 years for patients with pancolitis, and after 15 years for those with left-sided disease.

The screening interval should decrease with increasing duration of disease. A summary of the BSG recommendations is shown in Figure 3 (16). The CA G-CDHF position is similar in all respects.

Patients with primary sclerosing cholangitis, before or after transplantation, are at increased risk. The BSG recommends, and we concur, that these patients should undergo annual colonoscopy.

\section{FU T URE DIRECTIONS}

Carcinoma of the colon shows significant geographic variation, even in groups with similar genetic background. It is likely that factors such as diet play a significant role (17). Behavioural changes might mitigate the risk, but further research on population health, risk assessment and chemoprevention is required.

Biomarkers are cellular, biochemical, molecular and genetic markers by which normal or abnormal biological process can be recognized or monitored. They can illuminate pathological processes in asymptomatic individuals or identify individuals who are susceptible to cancer. Potential uses of biomarkers include:

1. Monitoring patients with established cancer for recurrence;

2. Early identification of asymptomatic patients;

\section{Early diagnosis of symptomatic patients;}

4. Surveillance of individuals known to be at high risk of cancer; and

5. Surrogate end-point markers for primary prevention strategies, such as chemoprevention.

Recent advances in molecular and cell biology have provided an excellent opportunity to develop and validate biomarkers for colorectal cancer screening and risk assessment.
Training of nonphysician endoscopists may be one option for addressing the shortage of physicians (18). A Iternatives to colonoscopy for imaging the colon, such as capsule technology, may affect the screening algorithm. Virtual colonoscopy, using helical computerized tomography or magnetic resonance imaging, has been the subject of a number of recent health technology assessments, including one by the Canadian C oordinating $\mathrm{O}$ ffice for $\mathrm{H}$ ealth Technology A ssessment (19). Presently, it is not felt that these techniques are suitable for mass screening, but they are certainly promising. A number of studies are underway in this area.

\section{ADDITIONAL RECOMMENDATIONS}

1. Ideally, provincial colon cancer screening policies and programs should be standardized. Recognizing that this is unlikely, we recommend that each province adopt a strategy that ensures equal access to resources.

2. The provinces should survey waiting lists for gastroenterology consultation and procedures. The availability of resources should be considered when developing screening programs.

3. Each province should develop screening programs for high risk patients. These patients should be informed of their risk and given access to appropriate screening and counselling.

4. Each province should devel op screening programs for patients at average risk. If FO BT is used, provision must be made for colonoscopic follow-up of positive tests.

5. The choice of testing for average risk patients should be determined by the availability of human and infrastructure resources. Colonoscopy is the screening tool of choice for patients at high risk for colorectal cancer.

6. Education programs need to be directed to health care providers and the public. The messages need to be congruent among the provinces.

7. The development of screening programs should be linked to evaluation of their impact, as well as research on cancer prevention through dietary and other means.

A CKN OW LED GEMENTS: We would like to acknowledge the contributions of $\mathrm{H}$ ealth $\mathrm{C}$ anada and the $\mathrm{C}$ anadian Society of Primary C are $\mathrm{G}$ astroenterology.

\section{REFERENCES}

1. M CLeod RS. Canadian Task Force on Preventive $\mathrm{H}$ ealth $\mathrm{C}$ are. Screening strategies for colorectal cancer: A systematic review of the evidence. C an J G astroenterol 2001;15:647-60.

2. $\mathrm{N}$ ational $\mathrm{C}$ ancer Institute of $\mathrm{C}$ anada: $\mathrm{C}$ anadian $\mathrm{C}$ ancer Statistics Toronto 2001. <www.ncic.cancer.ca/vgn/images/portal/cit_8675 1114/27/0/89485729cancerstatistics2003_en.pdf > (Version current at January 26, 2004>

3. Bond JH. Colon polyps and cancer. Endoscopy. 2003;35:27-35.

4. Wilson SM, Beahrs OH. The curative treatment of carcinoma of the sigmoid, rectosigmoid, and rectum. A nn Surg 1976;183:556-65.

5. G rady W M. G enetic testing for high-risk colon cancer patients. G astroenterology 2003;124:1574-94. 
6. N ational $\mathrm{C}$ ancer Institute of $\mathrm{C}$ anada. $\mathrm{C}$ anadian $\mathrm{C}$ ancer Statistics 2002. Toronto: The Institute, 2002. <www.ncic.cancer.ca/vgn/ images/portal/cit 86751114/27/0/89485729cancerstatistics2003 en. pdf > (Version current at January 26, 2003).

7. Johns LE, H oulston RS. A systematic review and meta-analysis of familial colorectal cancer risk. A m J G astroenterology 2001;96:2992-3003.

8. Winawer $S$, Fletcher R, Rex D, et al. G astrointestinal Consortium Panel. Colorectal cancer screening and surveillance: Clinical guidelines and rationale - update based on new evidence. Gastroenterology 2003;124:544-60.

9. Cairns S, Scholefield JH. Guidelines for colorectal cancer screening in high risk groups. G ut 2002;51(Supp 5):V 1-2.

10. Burke W, Petersen $G$, Lynch $P$, et al. Recommendations for followup care of individuals with an inherited predisposition to cancer. I. $\mathrm{H}$ ereditary non polyposis colon cancer. Cancer G enetics Studies Consortium. JA M A 1997;277:915-9.

11. Choi PM, N ugent FW, Schoetz DJ Jr, et al. Colonoscopic surveillance reduces mortality from colorectal cancer in ulcerative colitis. G astroenterology 1993;105:418-24.

12. Technical report for the national committee on colorectal cancer screening. H ealth C anada, 2002. <www.hc-sc.gc.ca/pphbdgspsp/publicat/ncccs-cndcc/pdf/ccstechrep_e.pdf > Version current at January 26, 2004).
13. Terry M B, N eugut A I, Bostick RM, Potter JD, H aile RW, Fenoglio-Preiser CM. Reliability in the classification of advanced colorectal adenomas. C ancer Epidemiol Biomarkers Prev 2002;11:660-3.

14. Winawer SJ, Zauber A G. The advanced adenoma as the primary target of screening. Gastrointest Endosc Clin N A m 2002;12:1-9.

15. Vasen H F, Watson P, M ecklin JP, Lynch HT. N ew clinical criteria for hereditary nonpolyposis colorectal cancer (H N PCC, Lynch syndrome) proposed by the International Collaborative $\mathrm{G}$ roup on H N PC C. G astroenterology 1999;116:1453-6.

16. Eaden JA, M ayberry JF. British Society for G astroenterology. The A ssociation of Coloproctology for $\mathrm{G}$ reat Britain and Ireland. $G$ uidelines for screening and surveillance of asymptomatic colorectal cancer in patients with inflammatory bowel disease. $\mathrm{G}$ ut 2002;51(Suppl V):V 10-2.

17. Fung $T, H u F B$, Fuchs $C$, et al. $M$ ajor dietary patterns and the risk of colorectal cancer in women. A rch Intern M ed 2003;163:309-14.

18. Rabeneck L, Paszat LF. C olorectal cancer screening in C anada: W hy not consider nurse endoscopists? CM AJ 2003;169:206-7.

19. Virtual colonoscopy pre-assessment. Canadian Coordinating 0 ffice for $\mathrm{H}$ ealth Technology A ssessment No 9, O ctober 2002. $<$ www.ccohta.ca/publications/pdf/N 09 _virtual colonoscopy_preassess _e.pdf> (Version current January 26, 2004) 


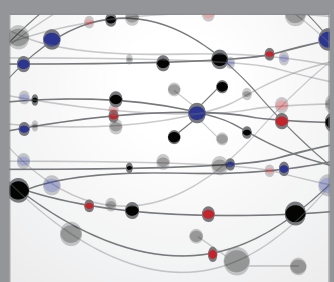

The Scientific World Journal
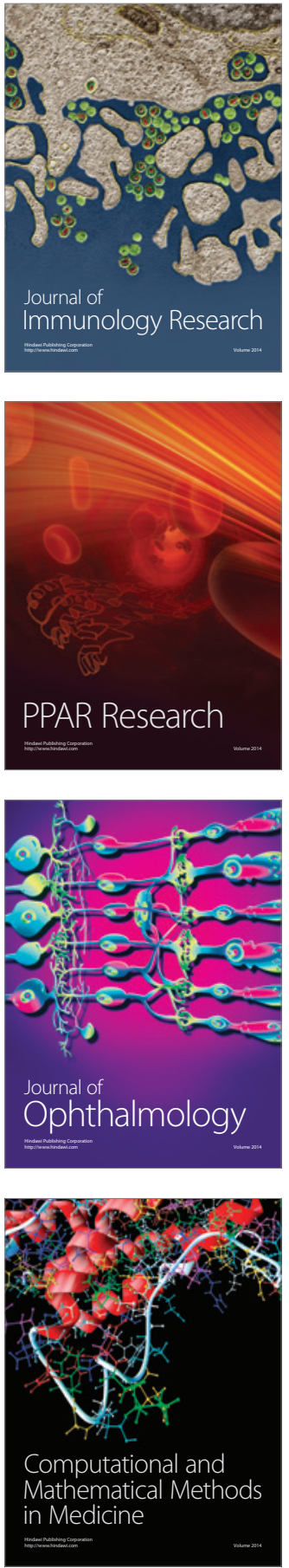

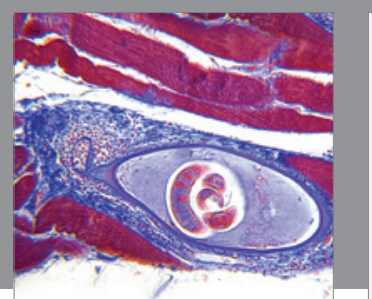

Gastroenterology Research and Practice

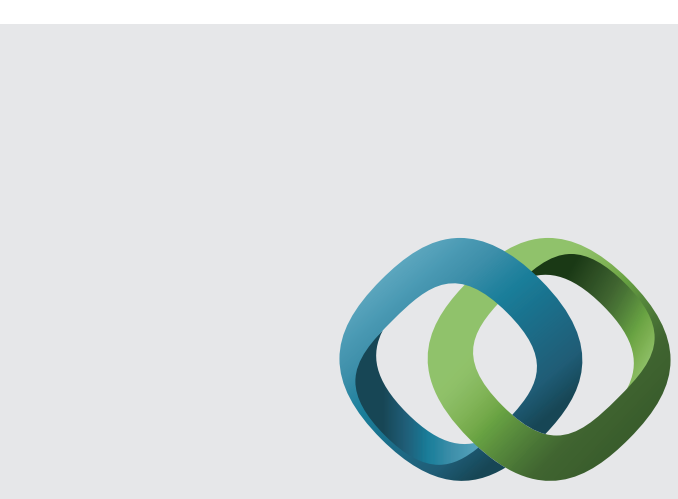

\section{Hindawi}

Submit your manuscripts at

http://www.hindawi.com
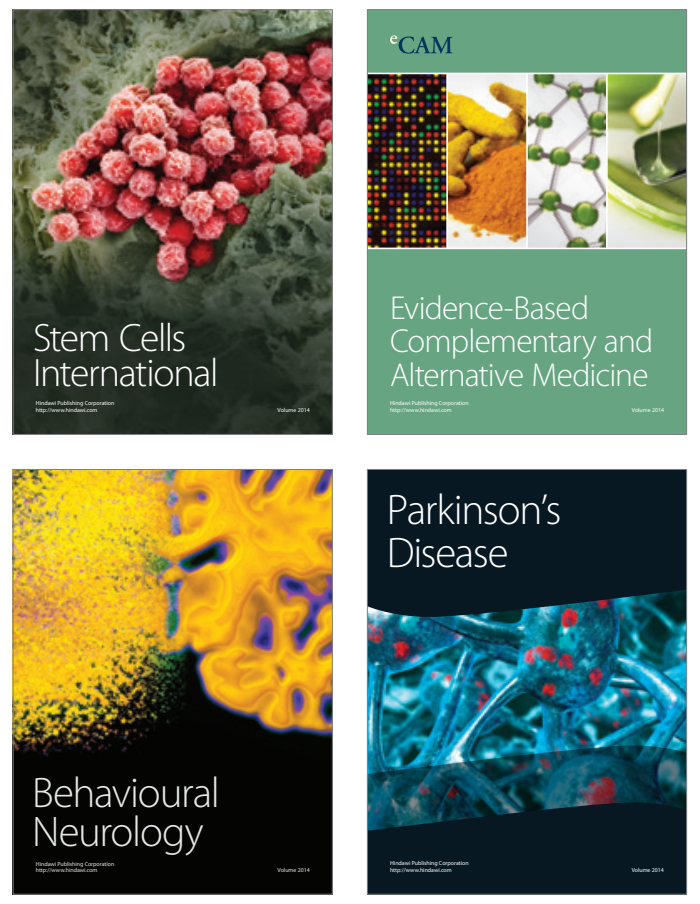
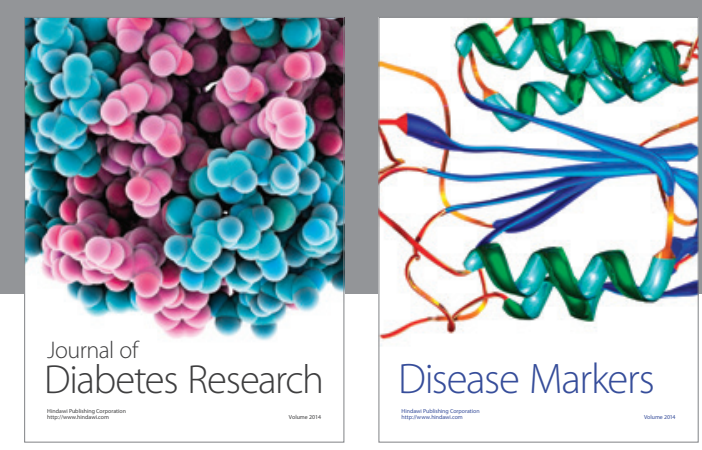

Disease Markers
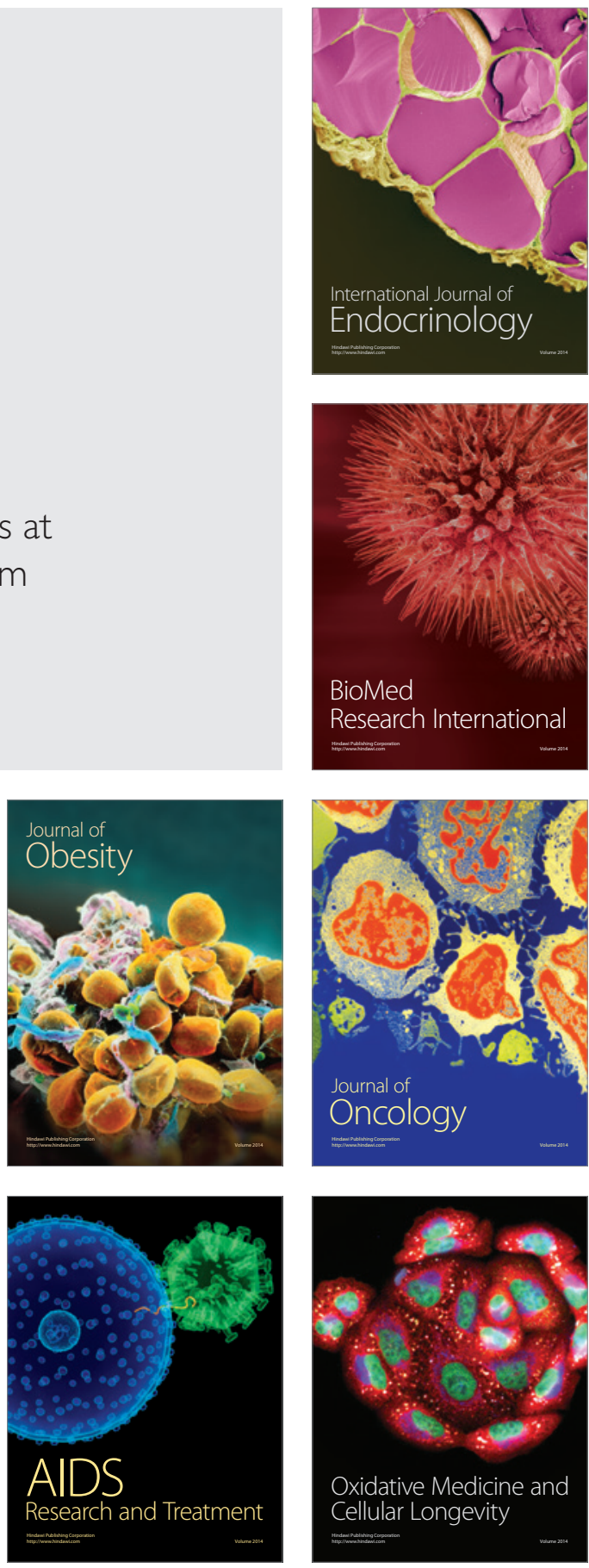